\title{
BMJ Open Prevalence, clinical relevance and predictive factors of medication discrepancies revealed by medication reconciliation at hospital admission: prospective study in a Swiss internal medicine ward
}

Olivier Giannini, ${ }^{1}$ Nicole Rizza, ${ }^{2}$ Michela Pironi, ${ }^{2}$ Saida Parlato, ${ }^{2}$ Brigitte Waldispühl Suter, ${ }^{3}$ Paola Borella, ${ }^{1}$ Alberto Pagnamenta, ${ }^{4,5}$ Liat Fishman, ${ }^{6}$ Alessandro Ceschi ${ }^{7,8}$

To cite: Giannini 0, Rizza N, Pironi M, et al. Prevalence, clinical relevance and predictive factors of medication discrepancies revealed by medication reconciliation at hospital admission: prospective study in a Swiss internal medicine ward. BMJ Open 2019;9:e026259. doi:10.1136/ bmjopen-2018-026259

- Prepublication history for this paper is available online. To view these files, please visit the journal online (http://dx.doi org/10.1136/bmjopen-2018026259).

$\mathrm{OG}$ and $\mathrm{NR}$ contributed equally.

OG and NR shared the first coauthorship.

Received 23 August 2018 Revised 15 February 2019 Accepted 4 April 2019

Check for updates

(C) Author(s) (or their employer(s)) 2019. Re-use permitted under CC BY-NC. No commercial re-use. See rights and permissions. Published by BMJ.

For numbered affiliations see end of article.

Correspondence to

Dr Olivier Giannini;

olivier.giannini@eoc.ch and Miss

Nicole Rizza;

nicole.rizza@eoc.ch

\section{ABSTRACT}

Objective Medication reconciliation (MedRec) is a relevant safety procedure in medication management at transitions of care. The aim of this study was to evaluate the impact of MedRec, including a best possible medication history (BPMH) compared with a standard medication history in patients admitted to an internal medicine ward.

Design Prospective interventional study. Data were analysed using descriptive statistics followed by univariate and multivariate Poisson regression models and a zeroinflated Poisson regression model.

Setting Internal medicine ward in a secondary care hospital in Southern Switzerland.

Participants The first 100 consecutive patients admitted in an internal medicine ward.

Primary and secondary outcome measures Medication discrepancies between the medication list obtained by the physician and that obtained by a pharmacist according to a systematic approach (BPMH) were collected, quantified and assessed by an expert panel that assigned a severity score. The same procedure was applied to discrepancies regarding allergies. Predicting factors for medication discrepancies were identified.

Results The median of medications per patient was 8 after standard medication history and 11 after BPMH. Total admission discrepancies were 524 (5.24 discrepancies per patient) with at least 1 discrepancy per patient. For 47 patients, at least one discrepancy was classified as clinically relevant. Discrepancies were classified as significant and serious in $19 \%$ and $2 \%$ of cases, respectively. Furthermore, $67 \%$ of the discrepancies were detected during the interview conducted by the pharmacist with the patients and/or their caregivers. The number of drugs used and the autonomous management of home therapy were associated with an increased number of clinically relevant discrepancies in a multivariable Poisson regression model.

Conclusion Even in an advanced healthcare system, a standardised MedRec process including a BPMH represents an important strategy that may contribute to

\section{Strengths and limitations of this study}

- This is the first Swiss study aimed at investigating the clinical relevance of a systematic medication reconciliation (MedRec) process at hospital admission.

- The methodology of the MedRec process was based on the detailed recommendations of the programme progress! Medication Reconciliation conducted at a national level by the Swiss Patient Safety Foundation.

- The expert panel was external to the internal medicine ward and was composed of different interprofessional expert profiles.

- The number of participants included in this study is limited.

- This study was performed in an internal medicine ward in a single hospital, and therefore generalizability is limited.

avoid a notable number of clinically relevant discrepancies and potential adverse drug events.

\section{INTRODUCTION}

Errors related to drug therapy are among the most frequent in healthcare systems and even nowadays constitute an unsolved public health issue. More than $60 \%$ of drugs errors arise at transitions of care (ie, at hospital admission and transfer or discharge of the patients). ${ }^{1-3}$ Up to $67 \%$ of patients' medication histories recorded on admission to hospital have one or more errors, and $30 \%-80 \%$ of patients have a discrepancy between the medicines ordered in the hospital and those they were taking at home. ${ }^{45}$ A preventable adverse drug 
event (ADE) has an estimated cost of $\$ 8750$; ADEs at a community hospital were associated with an increased adjusted cost of $\$ 3420$ and an adjusted increase in the length of hospital stay by 3 days according to the American Institute of Medicine and the Agency for Healthcare Research and Quality. ${ }^{6}$ In Switzerland, we do not have current data concerning medication errors and ADEs. ${ }^{7}$ In the past, Swiss studies have estimated that approximately $8 \%$ of all patients experienced an ADE during their hospital stay, and between $4 \%$ and $7 \%$ of hospital admissions are directly ascribed to ADEs. ${ }^{7-9}$ Research carried out in other countries showed similar, if not higher rates. ${ }^{10}{ }^{11}$ According to further Swiss studies, about one-third of the ADEs leading to hospital admission could be attributed to a medication error, therefore potentially avoidable. ${ }^{689}$ In an international survey of the Commonwealth Fund, $5.3 \%$ of the Swiss citizens declared that in the course of the previous 2 years, they had received a wrong drug or dosage at least once from a health specialist. ${ }^{12}$ The risk factors for medication errors are numerous and often linked to human factors. ${ }^{13-16}$

Medication reconciliation (MedRec) is a systematic process carried out by healthcare professionals with the aim of obtaining the most complete and accurate information about the drugs and other products regularly taken by patients. It involves compiling a complete, exact list of all patient's drugs and remedies (best possible medication history (BPMH)) with the involvement of the patient and/or family members and the use of such a list to adapt prescriptions. Ideally, the MedRec process should take place at every change in the care context, from admission to discharge and also during transfers, as recommended by the WHO. ${ }^{4}$ Data from the international literature show how fundamental the realisation of such a process is in preventing medication errors. ${ }^{5} 1718$ In a study conducted in a Swiss teaching hospital, $9 \%$ of the drugs taken by hospitalised patients in a cardiological setting were only detected by means of a systematic medication history. ${ }^{19}$

Even though Switzerland is a country with a modern public healthcare system, which is easily accessible and therefore considered efficient and innovative, ${ }^{20}$ there is a paucity of experience regarding the conduction of MedRec. Within the quality strategy of the Swiss Confederation Public Health System, the Patient Safety Foundation Switzerland thus conducted the programme progress! Medication Reconciliation in the period 2014-2017. The aim of the programme progress! was to improve patient safety by promoting the implementation of a systematic MedRec process in acute care hospitals. ${ }^{21}$ Within the programme, a group of hospitals tested the feasibility of introducing MedRec on admission. Our institution, which is a secondary care hospital and is part of the public hospital network of Southern Switzerland (Ente Ospedaliero Cantonale), participated as one of the eight Swiss hospitals taking part in the programme progress!.

\section{METHODS}

\section{Study design}

We designed an interventional prospective study in the context of the programme progress!. The aims of the study were to investigate the number and types of medication discrepancies between a standard physician-acquired medication history and a pharmacist-acquired BPMH, and to evaluate their potential clinical relevance to cause an $\mathrm{ADE}$.

\section{Study setting}

This investigation was performed in an internal medicine unit (total beds 64, number of admissions/year 2731 in 2016) of our hospital serving a population of 50000 inhabitants in Southern Switzerland.

A pharmacist (0.5 FTE) was dedicated to the programme for 2years. The pharmacist was trained in MedRec during two full-day workshops organised by the Patient Safety Foundation Switzerland (https://www.patientensicherheit.ch). The workshops included presentations by experts, discussion groups and role-playing exercises in taking a BPMH. The pharmacist was completely integrated in the internal medicine team and had unrestricted access to the electronic medical records (EMRs) system. The criteria of MedRec were based on the methodology of the programme progress! programme. ${ }^{21}$ Accordingly, during weekdays, the BPMH should take place within 24 hours from admission, and if the patient is admitted on the weekend, it should take place until 07:00 hours, Tuesday morning (the same rule applied for statutory holidays). The BPMH should be based on at least two information sources regarding the patient's treatment, one of which should always be, when possible, the structured interview with the patient and/or family members. According to national and international recommendations, guidelines for the interview were also created as a memory aid for all the interviews carried out by the pharmacist. ${ }^{21}$ Other sources of information were the medication list provided by the community pharmacy, the primary care physician, the nursing home and home care. Patients or their relatives were also requested to bring their drug packages to the hospital. Information was collected by telephone or sent by fax or email.

\section{Study population}

The first 100 patients admitted to our internal medicine ward from 2 May 2016 were included in the study. We only excluded terminally ill (life expectancy of few days) patients.

\section{Data collection}

For all patients, the medication history was first obtained as usual by a junior resident and was documented in the EMR. The BPMH was obtained by the pharmacist from Monday to Friday between 08:30 and 18:00 hours. The BPMH included questions about over-the-counter medications, including vitamins, minerals and supplements. The duration of the BPMH, including the interview with 
the patient, and generally of the whole MedRec process, was recorded. Data on the patient's characteristics and medications (Anatomical Therapeutic Chemical (ATC) code) were collected. ${ }^{22}$ The medication list obtained by the pharmacist was documented in the EMR system, which was adapted to integrate the new preadmission list in the list previously documented by the doctor. The medication discrepancies were automatically visible on this page. Subsequently, the medications list on admission after the standard physician-acquired medication history was compared with the list obtained by the pharmacist after the BPMH: the number and type of medication discrepancies between the standard physician-acquired medication history and the BPMH were recorded. Inpatient medication orders on admission were documented on the EMR by electronic prescription order. The medication discrepancies were classified as follows: omissions of drug; commission errors (unjustified additions of medication not used before admission); and incorrect drug strength, formulation, administration time or drug name. The medication discrepancies were communicated to the physician in charge using an electronic message system, and the physician adapted the medication orders in the EMR accordingly. The pharmacist recorded the time dedicated to the interview with the patients and/or caregivers and that dedicated to the whole MedRec process. In a second step, a panel of experts was created in order to classify the discrepancies according to their potential clinical relevance. The panel included an experienced clinical pharmacist (not the same person who conducted the BPMH), a senior physician with board certification in clinical pharmacology and toxicology, and a senior internal medicine physician. In agreement to a method described elsewhere ${ }^{23}$ medication discrepancies were classified according to the potential to cause an ADE into the following severity categories: non-relevant (ie, unlikely to cause patient discomfort or clinical deterioration), relevant as significant (ie, with the potential to cause moderate discomfort or clinical deterioration) or relevant as serious (ie, with the potential to cause severe discomfort or clinical deterioration) and non-classifiable (ie, insufficient information available to classify). The assessment of the clinical relevance was performed using the information of the BPMH and the patients' EMR. The same procedure was applied to allergies, drugs and/or food intolerances. Patient data and discrepancies were recorded in an Excel spreadsheet V.2013 (Microsoft Office for Windows, Microsoft Corporation, WA, USA) for further analysis.

\section{Data analysis}

Descriptive statistics are presented as mean with SD or as median with IQR for quantitative data, as appropriate, whereas qualitative data are presented as absolute numbers with percentages. Potential predictor variables of all discrepancies were first selected in te univariable regression model (Poisson regression or negative binomial regression as appropriate) and thereafter included in a multivariable regression model (Poisson regression or negative binomial regression as appropriate). Incidence rate ratios with the corresponding 95\% CIs were presented. All independent variables used in the previous regression model were introduced in a zero-inflated Poisson regression model in order to identify potential predictors of only clinically relevant discrepancies. For the latter discrepancies, we used a zero-inflated model because we observed an excess of zeros. All tests were conducted two-sided, and a $p$ value of $<0.05$ is considered statistically significant. Stata V.15.0 was used for all statistical analyses.

\section{Patient and public involvement}

The development of the research question and outcome measures was strongly informed by patients' priorities, as one of the main aims of the study was to assess the potential clinical relevance of ADEs.

Patients were not involved in the design of this study.

Patients were not involved in the recruitment. Patients were involved in the conduct of the study: systematic patient interviews between the study pharmacist and patients were a core component of the intervention.

Beyond this publication, there is no plan for dissemination of the results to study participants.

Table 1 Characteristics of the study population $(n=100)$

Age (years)

Mean 74.8

(Min. 25, max.

93), SD 14.5

$\mathrm{n}(=\%)$

\section{Sex}

$\begin{array}{ll}\text { Male } & 45 \\ \text { Female } & 55\end{array}$

Residence

Home

91

Rest home

7

Others

2

Management of home therapy

\begin{tabular}{lr} 
Autonomous & 59 \\
Assistance from family & 18 \\
Assistance from caregivers & 23 \\
Admission type & \\
Emergency & 90 \\
Planned & 5 \\
Transfer (from internal/external unit) & 5 \\
Admission day & \\
Weekday (Monday 07:00-Friday 12:00) & 52 \\
Weekend (Friday 12:00-Monday 07:00) & 47 \\
Holiday & 1 \\
\hline
\end{tabular}


Table 2 Number of medications per patient detected after standard drug history and after the BPMH

\begin{tabular}{llllllll}
\hline & \multicolumn{2}{l}{ Standard drug history } & \multicolumn{3}{l}{ BPMH } \\
\cline { 2 - 3 } & Median & Range & IQR & & Median & Range & IQR \\
\hline Regular drugs & 7.5 & $0-20$ & $5-10$ & 9 & $1-22$ & $6.0-11.5$ \\
Drugs as required & 0 & $0-7$ & $0-1$ & 2 & $0-10$ & $1-4$ \\
Overall therapy & 8 & $1-24$ & $5-11$ & 11 & $3-27$ & $8-14$ \\
\hline
\end{tabular}

$\mathrm{BPMH}$, best possible medication history.

\section{RESULTS}

One hundred patients were included and assessed from 2 May to 21 July 2016. The characteristics of the study population are summarised in table 1 .

The mean age was $74.8 \pm 14.5$ years (range $25-93$ years), and $59 \%$ of the patients were managing their medications by themselves, while the remaining were assisted by family and/or home caregivers. Ninety percent of the patients were admitted to the hospital through the emergency department, and $52 \%$ were admitted during weekdays.

The whole MedRec process took on average $47 \pm 18 \mathrm{~min}$ (range 15-110 min) with a mean duration of the structured interviews with patients and/or carers of $19 \pm 10 \mathrm{~min}$ (range 5-50 min). On average, 3.14 \pm 1.04 information sources (range 1-6) were used to retrieve information about medications used by patients, and the most used source of information was the structured interview with patients and/or carers, which was performed in $92 \%$ of the cases. The medication packages were used for inspection in $51 \%$ of the cases, and in $32 \%$ the drug information was verified with the patient's pharmacy. For three patients, we used only one source of information for the BPMH. Two of them were residents in elderly homes, and it was not possible to perform the interview with the patients and/or caregivers, so only the therapy plan provided by the nursing home was used. For the third patient, only the structured interview was performed.

The mean number of medications per patient detected was $8.57 \pm 4.79$ (range 1-24) by performing a standard drug history and 11.56 \pm 5.17 (range 3-27) after BPMH, which means that with the standard drug history, an average of three drugs per patient was omitted (table 2).

A total of 524 medication discrepancies were detected with a mean of $5.24 \pm 3.08$ discrepancies per patient (range 1-16, median 5). A minimum of one discrepancy was detected for every patient. Medication discrepancies were classified in $328(63 \%)$ cases as drug omission, $28(5 \%)$ as drug addition and the remaining $168(32 \%)$ were an incorrect drug strength, formulation, administration time or name. Sixty-seven per cent $(n=353)$ of the discrepancies were detected by interviewing patients and/or carers.

The expert panel evaluated 111 (21\%) discrepancies as clinically relevant, that is, as having the potential to cause an ADE: 100 (19\%) discrepancies were rated as significant (ie, with the potential to cause a minor to moderate $\mathrm{ADE}$ ), and $11(2 \%)$ were rated as serious (ie, with the potential to cause a serious ADE). Forty-seven patients were exposed to at least one clinically relevant discrepancy. The clinical relevance of the identified discrepancies is presented in table 3 .

In $32(28.8 \%)$ of the clinically relevant discrepancies, drugs belonging to the cardiovascular system of the ATC group ${ }^{22}$ were involved, followed by drugs belonging to the nervous system group $(n=25,22.5 \%)$ and to the alimentary track and metabolism group $(n=15,13.5 \%)$. Details of the ATC group related to medication discrepancies are listed in table 4.

Thirteen discrepancies (mean $0.13 \pm 0.42$ discrepancy/ patient, range 0-2) regarding drug allergies and intolerances were identified for the 100 patients in the study. All such discrepancies were classified as omission of information. Two discrepancies $(15 \%)$ were classified as clinically relevant with the potential to cause a minor to moderate ADE, while four discrepancies $(31 \%)$ were classified as harmless; for seven discrepancies (54\%), the expert panel did not have enough information to classify them.

A high number of drugs used was associated with an increased number of total discrepancies (table 5). Living at home was associated with an augmented number of total discrepancies, which was statistically significant only in the multivariable regression model (table 5).

The number of drugs used and autonomous home therapy management were associated with an increased number of clinically relevant discrepancies (table 6).

In addition, older age, male gender and admission during weekend or holidays were associated with an

Table 3 Clinical relevance defined by the expert panel of the medication discrepancies detected by performing the best possible medication history and the number of patients involved

\begin{tabular}{|c|c|c|c|c|}
\hline \multirow[b]{2}{*}{$\begin{array}{l}\text { Clinically non-relevant } \\
\text { discrepancies }\end{array}$} & \multicolumn{2}{|c|}{$\begin{array}{l}\text { Discrepancies } \\
(n=524)\end{array}$} & \multicolumn{2}{|l|}{$\begin{array}{l}\text { Patients } \\
\text { involved } \\
(n=100)\end{array}$} \\
\hline & 411 & $(79 \%)$ & 98 & \\
\hline $\begin{array}{l}\text { Clinically relevant } \\
\text { discrepancies }\end{array}$ & & & & 47 \\
\hline Significant & 100 & $(19 \%)$ & 44 & \\
\hline Serious & 11 & $(2 \%)$ & 8 & \\
\hline $\begin{array}{l}\text { Non-classifiable } \\
\text { discrepancies }\end{array}$ & 2 & $(0 \%)$ & 2 & \\
\hline
\end{tabular}


Table 4 Classification of the medication discrepancies according to the ATC classification system ${ }^{22}$

\begin{tabular}{|c|c|c|}
\hline ATC group & $\begin{array}{l}\text { Total } \\
\text { n (\%) }\end{array}$ & $\begin{array}{l}\text { Clinically } \\
\text { relevant } \\
\mathrm{n}(\%)\end{array}$ \\
\hline $\begin{array}{l}\text { A: alimentary tract and } \\
\text { metabolism }\end{array}$ & $139(26.5)$ & 15 (13.5) \\
\hline $\begin{array}{l}\text { B: blood and haematopoietic } \\
\text { system }\end{array}$ & $25(4.8)$ & $5(4.5)$ \\
\hline C: cardiovascular system & $83(15.8)$ & $32(28.8)$ \\
\hline D: dermatologicals & $11(2.1)$ & $0(0)$ \\
\hline $\begin{array}{l}\text { G: genitourinary system and } \\
\text { sexual hormones }\end{array}$ & $11(2.1)$ & $2(1.8)$ \\
\hline $\begin{array}{l}\mathrm{H} \text { : endocrine system } \\
\text { (without sexual hormones and } \\
\text { insulin) }\end{array}$ & $9(1.7)$ & $4(3.6)$ \\
\hline J: systemic anti-infective drugs & $4(0.8)$ & $4(3.6)$ \\
\hline $\begin{array}{l}\text { M: musculoskeletal system and } \\
\text { joints }\end{array}$ & $34(6.5)$ & $3(2.7)$ \\
\hline $\mathrm{N}$ : nervous system & $118(22.5)$ & $25(22.5)$ \\
\hline R: respiratory system & $43(8.2)$ & $11(9.9)$ \\
\hline S: sensory organs & $26(5.0)$ & $7(6.3)$ \\
\hline No ATC category & $21(4.0)$ & $3(2.7)$ \\
\hline Total & 524 & 111 \\
\hline
\end{tabular}

The ATC groups not involved in medication discrepancies are not reported in the table.

ATC, Anatomical Therapeutic Chemical.

increased but statistically not significant risk for clinically relevant discrepancies when compared with younger and female patients or with patients admitted during weekdays. The type of admission (planned vs emergency) had no significant effect on the risk of discrepancies regarding both the number and the clinical relevance (tables 5 and $6)$.

\section{DISCUSSION}

To our knowledge, these are the first data that demonstrate the clinical relevance of a systematic MedRec process in acutely admitted patients to a Swiss internal medicine ward. The results of this study are important and worrying since they derive from a group of patients for whom responsibility was taken by a healthcare system considered among the most modern and avant-garde. ${ }^{20}$ Although in many healthcare systems MedRec has proven itself to be a valid measure for preventing unintended medication discrepancies and related ADE, in Switzerland, this process has been introduced and carried out on a limited scale only. ${ }^{24}$ We found a very high prevalence of unintentional medication discrepancies. Furthermore, we found at least one discrepancy per patient, and half of the patients presented a potentially harmful discrepancy. These rates are similar or even higher than those found in other studies. ${ }^{681325}$ The high prevalence of medication discrepancies found in our study is probably due to the fact that the pharmacist dedicates more time and effort to obtain a complete and accurate medication history than physicians. This observation is supported by a qualitative study which concluded that a barrier for physicians completing MedRec is that they consider care responsibilities a higher priority. ${ }^{26}$ The effort required to obtain an accurate preadmission medication list may be substantial and includes communication with community pharmacists, outpatient physicians, family members and caregivers, and the time spent reviewing pill bottles with patients. ${ }^{27-30}$ The large amount of time dedicated to the

Table 5 Potential predictor variables associated with the number of discrepancies (clinically relevant and not) in bivariate and multivariable Poisson regressions

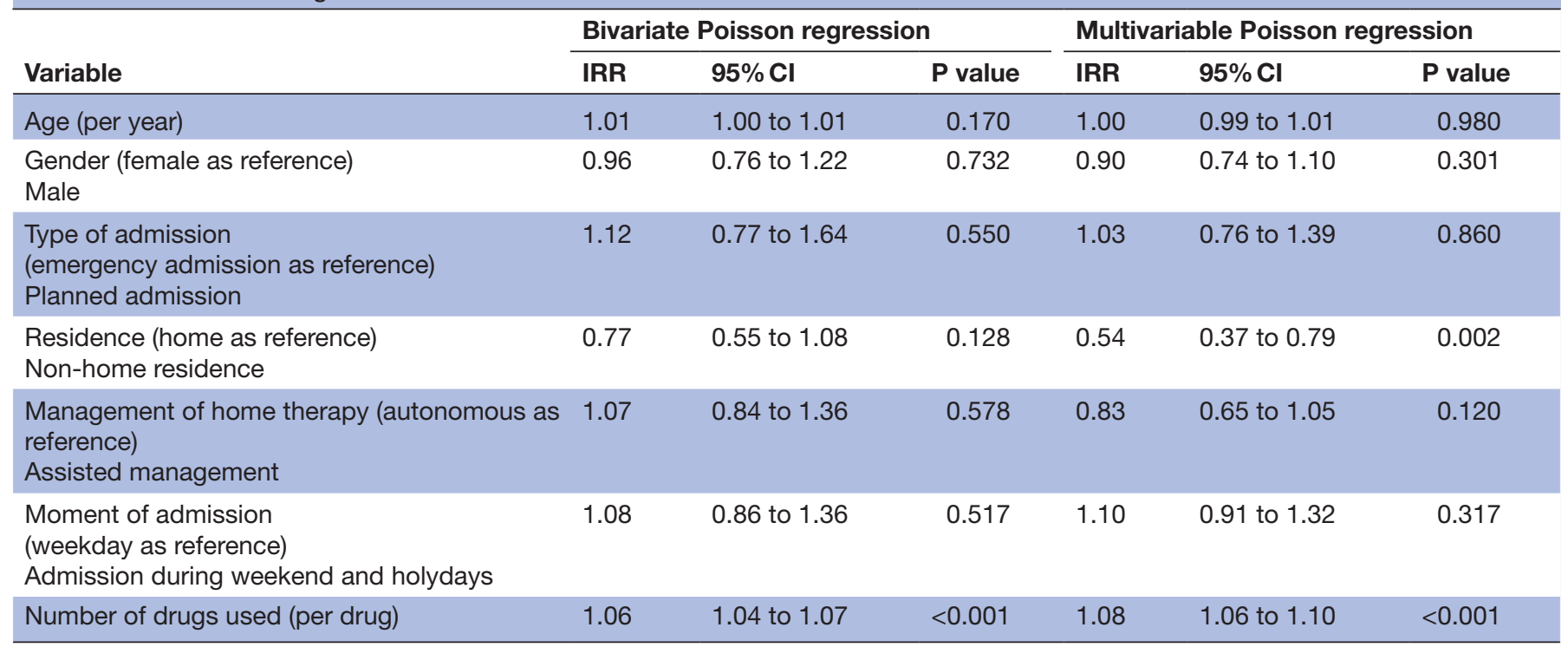

$\mathrm{IRR}$, incidence rate ratio. 
Table 6 Potential predictor variables associated with the number of clinically relevant discrepancies in zero-inflated Poisson regression

\begin{tabular}{|c|c|c|c|}
\hline \multirow[b]{2}{*}{ Variable } & \multicolumn{3}{|c|}{ Zero-inflated Poisson regression } \\
\hline & IRR & $95 \% \mathrm{Cl}$ & $P$ value \\
\hline Age (per year) & 1.02 & 1.00 to 1.04 & 0.090 \\
\hline Male & 1.44 & 0.94 to 2.21 & 0.098 \\
\hline \multicolumn{4}{|c|}{ Type of admission (emergency admission as reference) } \\
\hline \multicolumn{4}{|l|}{ Residence (home as reference) } \\
\hline Non-home residence & 1.96 & 0.74 to 5.17 & 0.174 \\
\hline \multicolumn{4}{|c|}{ Management of home therapy (autonomous as reference) } \\
\hline Assisted management & 0.40 & 0.22 to 0.71 & 0.002 \\
\hline \multicolumn{4}{|l|}{ Moment of admission (weekday as reference) } \\
\hline
\end{tabular}

IRR, incidence rate ratios.

interview, on average $19 \mathrm{~min}$ in our study, and the time needed for the whole reconciliation process, on average $47 \mathrm{~min}$, confirm the time-intensiveness of the process. The difficulty for junior doctors to undertake this process due to time constraints was generally observed during the whole period of the programme progress! Medication Reconciliation and was similarly experienced in the other Swiss hospitals taking part in the programme. ${ }^{30}$

The comprehensive recording of drug therapy at admission lays the foundation for an optimal, safe drug prescription in the hospital and thereafter for an efficient review of drug therapy in case of internal transfer and at discharge. ${ }^{29-33}$ The BPMH reveals all the drugs and remedies a patient takes at the time of admission, those subject to medical prescription, as well as those sold over the counter, phototherapy and food integrators. Although often forgotten and omitted, these are very important as they can interact with new drugs and subsequently cause adverse events. ${ }^{34}$

This study demonstrated the importance of including a structured interview with patients and/or their carers in the BPMH process since $67 \%$ of the discrepancies were revealed in this way. Unfortunately, the structured medication history interview is not given sufficient importance in clinical activity, nor in pregraduate and postgraduate education, as it is often carried out quickly, and not systematically, by junior doctors on the ward or in the emergency room. ${ }^{35}$ Furthermore, usually only one source of information is accessed and the medical history often contains incomplete information on the drug therapy taken by the patient at home and is therefore not suitable for safe drug prescribing. ${ }^{37} 38$ The BPMH is carried out following a systematic procedure that allows gathering together all available information on a patient's drug therapy. ${ }^{1-415}$ In addition to these benefits, MedRec may promote medication adherence and the patient's satisfaction, optimises communication within the care team and among the various providers of care (caregivers, family members, attending practitioner and pharmacist) and makes the process of taking history and drug prescription more efficient, thus improving the interdisciplinary teamwork. $^{27}$

Our finding that polypharmacy and autonomous patient drug management were identified as risk factors for clinically relevant discrepancies is in accordance with previous reports. ${ }^{11363940}$ In our study, age and the moment of admission were not associated with increased discrepancies, as in other studies. This might be explained by our small sample size. The list of the medications frequently involved in the discrepancies was also predictable and similar to that found in other studies and to the medications that are generally considered to be responsible for a substantial part of ADEs in hospitalised patients. ${ }^{1} 192540$

Although our study focused only on hospital admission, there is some evidence that the systematic MedRec process may be a valuable measure in all situations involving transitions of care in which patients may be exposed to the risk of medication discrepancies, particularly in patients with chronic disease. ${ }^{24}$

Participating in the programme progress! enabled our hospital to lay the foundations for the improvement of the medication process. It is hoped that the widespread introduction of intersectoral electronic health records in Switzerland in the coming years will facilitate the systematic review of medications and improve drug safety at the transition of care, as it has been demonstrated for other countries. $^{2141}$

In line with the experiences of other teams, involving pharmaceutical staff gave us the opportunity to learn about more efficient and sustainable models to apply in 
clinical practice, such as the creation of checklists and training courses, and contributed to the intensification of interprofessional collaboration among physicians, nursing staff and hospital pharmacy. ${ }^{33} 354142$

The results of this study, combined with all the experiences acquired during the programme progress! in the eight pilot hospitals, have led to the creation and recent release of specific recommendations by the Patient Safety Foundation Switzerland at the national level. ${ }^{30}$ The great challenge will be, on the one hand, to mobilise enough resources in a healthcare system that is already very expensive, and on the other hand, to involve all the players in the process, clearly defining the roles of those who are best qualified and able to perform and supervise the MedRec process within hospitals.

\section{Strengths and weaknesses of the study}

One strength of this study is its integration in the national programme progress! Medication Reconciliation, promoted by the Swiss Patient Safety Foundation. This permitted us to apply a structured and well-established methodology for MedRec. Our method was strengthened by the fact that for the BPMH, the pharmacist used a mean of three information sources regarding the patient's treatment and that in $92 \%$ of the cases the structured interview with patients and/or carers was performed. Another strength of this study is that the expert panel, which was external to the internal medicine ward, was interprofessional and consisted of different profiles with different expertise and responsibilities related to pharmacotherapy. An important limitation of the present study is that it did not assess the patients' relevant outcomes as mortality, incidence of ADEs, lengths of stay, readmissions and subsequent visits to the emergency department. Others studies investigated the association between MedRec and patients' outcomes but with inconclusive results calling for further research. ${ }^{43}{ }^{44}$ Others limitations that should be acknowledged are the limited number of participants and the fact that the study was performed in an internal medicine ward of a single hospital, thus limiting the generalizability of the findings. Furthermore, the fact that some physicians were informed about the programme progress! Medication Reconciliation and that some of them were trained in obtaining a BPMH may have influenced the results, although it is difficult to say in which direction.

\section{CONCLUSION}

Unintended medication discrepancies, which can be clinically relevant and cause ADE, should be considered a significant public health issue, even in an advanced and innovative healthcare system. The problem cannot be ignored and requires urgent action. The introduction of a standardised and systematic MedRec process, including a BPMH, is an effective strategy in detecting unintentional medication discrepancies.

\section{Author affiliations}

${ }^{1}$ Department of Internal Medicine, Ospedale Regionale di Mendrisio, Ente Ospedaliero Cantonale, Mendrisio, Ticino, Switzerland

${ }^{2}$ Hospital Pharmacy Service, Institute of Pharmacological Sciences of Southern Switzerland, Ente Ospedaliero Cantonale, Lugano, Switzerland

${ }^{3}$ Division of Clinical Informatics, Ente Ospedaliero Cantonale, Bellinzona, Switzerland

${ }^{4}$ Unit of Clinical Epidemiology, Ente 0spedaliero Cantonale, Bellinzona, Switzerland

${ }^{5}$ Division of Pneumology, University of Geneva, Geneva, Switzerland

${ }^{6}$ Patient Safety Foundation, Zurich, Switzerland

${ }^{7}$ Division of Clinical Pharmacology and Toxicology, Institute of Pharmacological Sciences of Southern Switzerland, Ente Ospedaliero Cantonale, Lugano, Switzerland ${ }^{8}$ Department of Clinical Pharmacology and Toxicology, University Hospital Zurich, Zurich, Switzerland

Acknowledgements The authors thank Professor Dr Stefano Bassetti, Department of Internal Medicine, University Hospital of Basel (Switzerland), for his kind suggestions and useful discussion, and Mariarosa Pascale, PhD, Clinical Trial Unit, Ente 0spedaliero Cantonale (Switzerland), for her help in editing this article.

Contributors OG, NR, MP, SP and AC participated in the conception and design of this study. NR and MP collected the data. OG, NR, MP, AP and AC analysed the data and interpreted the results. $O G, N R, M P$ and $A C$ drafted the article. All authors $(O G$, $\mathrm{NR}, \mathrm{MP}, \mathrm{SP}, \mathrm{BWS}, \mathrm{PB}, \mathrm{AP}, \mathrm{LF}$ and $\mathrm{AC}$ ) critically revised the manuscript and give final approval of the present version to be submitted. No patients or patient advisers where involved in this study.

Funding The authors have not declared a specific grant for this research from any funding agency in the public, commercial or not-for-profit sectors.

Competing interests LF reports grants from Swiss Federal Office of Public Health during the conduct of the study.

Patient consent for publication Not required.

Ethics approval Ethical approval was not required according to the decision of the ethics committee of the Canton of Zurich (Art.51 Abs.2 of the Swiss Human Research Act, 31.10.2014).

Provenance and peer review Not commissioned; externally peer reviewed.

Data sharing statement The data set of the study is available from the corresponding author on request.

Open access This is an open access article distributed in accordance with the Creative Commons Attribution Non Commercial (CC BY-NC 4.0) license, which permits others to distribute, remix, adapt, build upon this work non-commercially, and license their derivative works on different terms, provided the original work is properly cited, appropriate credit is given, any changes made indicated, and the use is non-commercial. See: http://creativecommons.org/licenses/by-nc/4.0/.

\section{REFERENCES}

1. Sullivan C, Gleason KM, Rooney D, et al. Medication reconciliation in the acute care setting: opportunity and challenge for nursing. J Nurs Care Qual 2005;20:95-8.

2. Kwan JL, Lo L, Sampson M, et al. Medication reconciliation during transitions of care as a patient safety strategy. Ann Intern Med 2013;158:397-403.

3. Perren A, Previsdomini M, Cerutti B, et al. Omitted and unjustified medications in the discharge summary. Qual Saf Health Care 2009;18:205-8.

4. World Health Organisation. The High 5s Project: interim report. 2013 www.who.int/patientsafety/implementation/solutions/high5s/High5_ InterimReport.pdf (Accessed Aug 2018).

5. National Institute for Health and Care Excellence. Medicines optimization: the safe and effective use of medicines to enable the best possible outcomes, NICE Guidelines. 2015 www.nice.org.uk/ guidance/ng5 (Accessed Aug 2018).

6. Wasserfallen J, Livio F, Buclin T, et al. Rate, type, and cost of adverse drug reactions in emergency department admissions. Eur J Intern Med 2001;12:442-7.

7. Fattinger $\mathrm{K}$, Roos $\mathrm{M}$, Vergères $\mathrm{P}$, et al. Epidemiology of drug exposure and adverse drug reactions in two swiss departments of internal medicine. Br J Clin Pharmacol 2000;49:158-67.

8. Hardmeier B, Braunschweig S, Cavallaro M, et al. Adverse drug events caused by medication errors in medical inpatients. Swiss Med Wkly 2004;134(45-46):664-70. 
9. Lepori V, Perren AF, Marone C. Adverse internal medicine drug effects at hospital admission [Unerwünschte intermedizinische Arzneimittelwirkungen bei Spitaleintritt]. Schweiz Med Wochenschr 1999:129:915-22.

10. Davies EC, Green CF, Taylor S, et al. Adverse drug reactions in hospital in-patients: a prospective analysis of 3695 patient-episodes. PLoS One 2009;4:e4439.

11. Budnitz DS, Pollock DA, Weidenbach KN, et al. National surveillance of emergency department visits for outpatient adverse drug events. JAMA 2006;296:1858-66.

12. Schwappach DL. Risk factors for patient-reported medical errors in eleven countries. Health Expect 2014;17:321-31.

13. Ashcroft DM, Lewis PJ, Tully MP, et al. Prevalence, Nature, Severity and Risk Factors for Prescribing Errors in Hospital Inpatients: Prospective Study in 20 UK Hospitals. Drug Saf 2015;38:833-43.

14. Meyer-Nikolic VA, Hersperger M, Herren D, et al. Fehlerquelle Medikamentenverordnung. Schweizerische Ärztezeitung 2011;92:1486-7.

15. Pippins JR, Gandhi TK, Hamann C, et al. Classifying and predicting errors of inpatient medication reconciliation. J Gen Intern Med 2008;23:1414-22.

16. Dean B, Barber N, Schachter M. What is a prescribing error? Qual Health Care 2000;9:232-7.

17. Mueller SK, Sponsler KC, Kripalani S, et al. Hospital-based medication reconciliation practices: a systematic review. Arch Intern Med 2012;172:1057-69.

18. Kwan JL, Lo L, Sampson M, et al. Medication reconciliation during transitions of care as a patient safety strategy: a systematic review. Ann Intern Med 2013;158:397-403.

19. Frei $P$, Huber LC, Simon RW, et al. Insufficient medication documentation at hospital admission of cardiac patients: a challenge for medication reconciliation. J Cardiovasc Pharmacol 2009;54:497-501.

20. Biller-Andorno N, Zeltner T. Individual Responsibility and Community Solidarity--The Swiss Health Care System. N Engl J Med 2015;373:2193-7.

21. Fishman L, Gehring K, Zimmermann C, et al. Medication Reconciliation in the Acute Care Hospital [Der systematische Medikationsabgleich im Akutspital]. Zürich: Stiftung für Patientensicherheit, 2015.

22. WHO Collaborating Centre for Drug Statistics Methodology. ATC/ DDD Index. 2018 www.whocc.no/atcddd/ (Accessed Aug 2018).

23. Cornish PL, Knowles SR, Marchesano R, et al. Unintended medication discrepancies at the time of hospital admission. Arch Intern Med 2005;165:424-9.

24. Fishman L, Brühwiler L, Schwappach D. [Medication safety in Switzerland: Where are we today?]. Bundesgesundheitsblatt Gesundheitsforschung Gesundheitsschutz 2018;61:1152-1158.

25. Tam VC, Knowles SR, Cornish PL, et al. Frequency, type and clinical importance of medication history errors at admission to hospital: a systematic review. CMAJ 2005;173:510-5.

26. Boockvar KS, Santos SL, Kushniruk A, et al. Medication reconciliation: barriers and facilitators from the perspectives of resident physicians and pharmacists. J Hosp Med 2011;6:329-37.

27. Nilsson N, Lea M, Lao Y, et al. Medication discrepancies revealed by medication reconciliation and their potential short-term and long-term effects: a Norwegian multicentre study carried out on internal medicine wards. European Journal of Hospital Pharmacy 2015;22:298-303.

28. van den Bemt PM, van der Schrieck-de Loos EM, van der Linden C, et al. Effect of medication reconciliation on unintentional medication discrepancies in acute hospital admissions of elderly adults: a multicenter study. J Am Geriatr Soc 2013;61:1262-8.

29. Drenth-van Maanen AC, Spee J, van Hensbergen L, et al. Structured history taking of medication use reveals iatrogenic harm due to discrepancies in medication histories in hospital and pharmacy records. J Am Geriatr Soc 2011;59:1976-7.

30. Patientensicherheit Schweiz. Erklärung Sichere Medikation an Schnittstellen. 2017 www.patientensicherheit.ch.

31. Damlien L, Davidsen N, Nilsen M, et al. Drug safety at admission to emergency department: an innovative model for PRIOritizing patients for MEdication Reconciliation (PRIOMER). Eur J Emerg Med 2017;24:333-9

32. Gardiner P, Sadikova E, Filippelli AC, et al. Medical reconciliation of dietary supplements: don't ask, don't tell. Patient Educ Couns 2015;98:512-7

33. Steurbaut $\mathrm{S}$, Leemans L, Leysen $\mathrm{T}$, et al. Medication history reconciliation by clinical pharmacists in elderly inpatients admitted from home or a nursing home. Ann Pharmacother 2010;44:1596-603.

34. Henriksen JP, Noerregaard S, Buck TC, et al. Medication histories by pharmacy technicians and physicians in an emergency department. Int J Clin Pharm 2015;37:1121-7.

35. Almanasreh $\mathrm{E}$, Moles $\mathrm{R}$, Chen TF. The medication reconciliation process and classification of discrepancies: a systematic review. $\mathrm{Br} \mathrm{J}$ Clin Pharmacol 2016;82:645-58.

36. Hellström LM, Bondesson Åsa, Höglund P, et al. Errors in medication history at hospital admission: prevalence and predicting factors. BMC Clin Pharmacol 2012;12:9.

37. Lea M, Barstad I, Mathiesen L, et al. Effect of teaching and checklist implementation on accuracy of medication history recording at hospital admission. Int J Clin Pharm 2016;38:20-4.

38. Urfer M, Elzi L, Dell-Kuster S, et al. Intervention to improve appropriate prescribing and reduce polypharmacy in elderly patients admitted to an internal medicine unit. PLoS One 2016;11:e0166359.

39. de Vries EN, Ramrattan MA, Smorenburg SM, et al. The incidence and nature of in-hospital adverse events: a systematic review. Qual Saf Health Care 2008;17:216-23.

40. Hias J, Van der Linden L, Spriet I, et al. Predictors for unintentional medication reconciliation discrepancies in preadmission medication: a systematic review. Eur J Clin Pharmacol 2017;73:1355-77.

41. Smith L, Mosley J, Lott S, et al. Impact of pharmacy-led medication reconciliation on medication errors during transition in the hospital setting. Pharm Pract 2015;13:634

42. Niederhauser A, Zimmermann C, Fishman L, et al. Implications of involving pharmacy technicians in obtaining a best possible medication history from the perspectives of pharmaceutical, medical and nursing staff: a qualitative study. BMJ Open 2018;8:e020566.

43. Cheema E, Alhomoud FK, Kinsara ASA, et al. The impact of pharmacists-led medicines reconciliation on healthcare outcomes in secondary care: A systematic review and meta-analysis of randomized controlled trials. PLoS One 2018;13:e0193510.

44. Redmond P, Grimes TC, McDonnell R, et al. Impact of medication reconciliation for improving transitions of care. Cochrane Database Syst Rev 2018;8:8. 